\title{
THE
}

UNIVERSITY

University of Rhode Island

OF RHODE ISLAND

DigitalCommons@URI

8-16-1971

\section{Crystal to Liquid-Crystal Transition Studied by Raman Scattering}

W. J. Borer

University of Rhode Island

S. S. Mitra

University of Rhode Island

C. W. Brown

University of Rhode Island, cbrownsails@uri.edu

Follow this and additional works at: https://digitalcommons.uri.edu/chm_facpubs

Terms of Use

All rights reserved under copyright.

\section{Citation/Publisher Attribution}

W. J. Borer, S. S. Mitra, \& Brown, C. W. (1971). Crystal to Liquid-Crystal Transition Studied by Raman Scattering. Physical Review Letters, 27(7), 379.

Available at: http://dx.doi.org/10.1103/PhysRevLett.27.379

This Article is brought to you for free and open access by the Chemistry at DigitalCommons@URI. It has been accepted for inclusion in Chemistry Faculty Publications by an authorized administrator of DigitalCommons@URI. For more information, please contact digitalcommons-group@uri.edu. 


\title{
Crystal to Liquid-Crystal Transition Studied by Raman Scattering
}

\author{
W. J. Borer and S. S. Mitra \\ Department of Electrical Engineering, University of Rhode Island, Kingston, Rhode Island 02881 \\ and \\ C. W. Brown \\ Department of Chemistry, University of Rhode Island, Kingston, Rhode Island 02881 \\ (Received 28 June 1971)
}

\begin{abstract}
Phase transitions of the nematic liquid crystal $p$-methoxy-benzylidine, $p-n$ butyl-aniline were studied by recording the low-frequency Raman spectrum. The intensity of the lattice Raman bands undergoes abrupt change at the crystalline-to-nematic phase transition temperature, with an indication of a hysteresis. The band totally disappears at the isotropic (liquid) phase.
\end{abstract}

The values of the transition temperature for the crystalline-to-nematic $(c-n)$ phase transition in $p$-methoxy-benzylidine, $p-n$ butyl-aniline (MBBA) given by various author $\mathrm{s}^{1-3}$ do not agree, and this is generally attributed to the presence of impurities. No investigation seems to have been made so far to compare the transition temperatures for the $c \rightarrow n$ and $n \rightarrow c$ transitions. The nematic to isotropic $(n-i)$ transition in MBBA has been investigated by Rayleigh scattering. ${ }^{4}$ Pretransitional phenomena in MBBA preceding the $i-n$ transition have also been reported. ${ }^{5}$ In this paper we report an investigation of temperature dependence of the low-frequency Raman-scattering spectrum of MBBA covering a range of temperature that includes both $c \rightarrow n$ and $n-i$ transitions.

Infrared and Raman studies of the $c-n$ transition have been reported for other liquid-crystalline materials, ${ }^{6-8}$ but no hysteresis was observed. However, hysteresis effects have been observed in electrical conductivity measurement on $p-$ anisylidene- $p^{\prime}$-biphenylamine $e^{9}$ and in measurements of shear resistance on ethyl-p-azoxy-benzoate at the isotropic to smectic transition. ${ }^{10}$

In this study the Raman spectrum of MBBA ${ }^{11}$ was measured as a function of temperature. An argon ion laser (4880 $)$ was sued as the light source. To insure against heating by the laser light a neutral density filter was used to reduce the power of the incident light to $2 \mathrm{~mW}$. A perpendicular scattering geometry was used. The spectrum was analyzed with a Spex 1400 double monochromator and photon-counting electronics. The sample was contained in a glass capillary tube $(0.7 \mathrm{~mm}$ i.d. and $1.4 \mathrm{~mm}$ o.d.), which was placed in a copper holder connected to a thermoelectric cooler/heater system providing a temperature stability of $\pm 0.1^{\circ} \mathrm{C}$ at temperatures near the $c-n$ phase transition and of $\pm 0.2{ }^{\circ} \mathrm{C}$ near the $n-i$ transition.

The spectrum was recorded from 0 to $250 \mathrm{~cm}^{-1}$ at various temperatures in all three phases. Typical spectra for all three phases are shown in Fig. 1. Two features of the spectra are worth noting: (i) structures around $100 \mathrm{~cm}^{-1}$ very pronounced in the crystalline phase, also present in the nematic phase but much reduced in intensity, and totally absent in the isotropic liquid phase. No detectable change of frequency could be noted as one went from $c$ to $n$ phase. (ii) A band around $176 \mathrm{~cm}^{-1}$ in the crystalline phase,

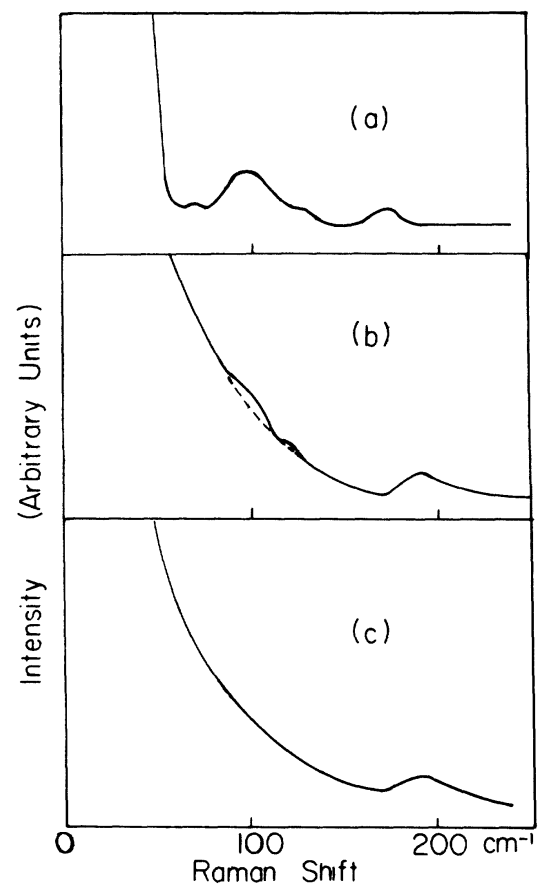

FIG. 1. Low-frequency Raman spectrum of MBBA. (a) Crystalline phase $\left(2^{\circ} \mathrm{C}\right)$; (b) nematic phase $\left(20^{\circ} \mathrm{C}\right)$; (c) isotropic phase $\left(45^{\circ} \mathrm{C}\right)$. 


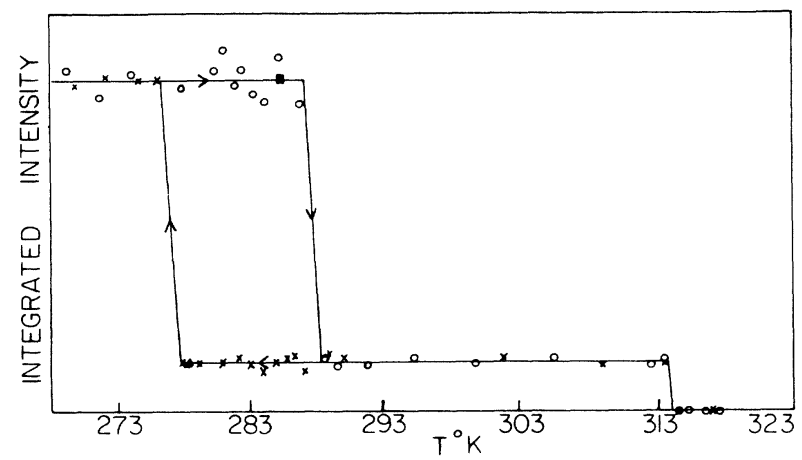

FIG. 2. Integrated intensity of the Raman band near $100 \mathrm{~cm}^{-1}$ plotted against temperature. Phase transitions occur at $277^{\circ} \mathrm{K}(n \rightarrow c), 288^{\circ} \mathrm{K}(c \rightarrow n)$, and $314^{\circ} \mathrm{K}$ $(n \rightarrow i)$. Circles represent heating; crosses, cooling. Rectangle represents recycled solid phase at $285.5^{\circ} \mathrm{K}$ kept for $24 \mathrm{~h}$. Triangle represents recycled nematic phase kept for $24 \mathrm{~h}$ at $278.3^{\circ} \mathrm{K}$.

abruptly moving to $189 \mathrm{~cm}^{-1}$ in the nematic phase, and remaining approximately at the same position through the liquid phase. The intensity of this band is comparable in all three phases. The structure around $100 \mathrm{~cm}^{-1}$ is therefore attributable to long-wavelength lattice modes. Whether they are of translational or librational origin cannot be ascertained at this stage. In any case such information is not relevant for the present discussion. It is significant to note that the intermolecular lattice vibrations persist in the nematic state, and the intensity of these bands may be used in the determination of the liquid-crystalline order parameter. Such studies are in progress and will be published elsewhere. The band at $176 \mathrm{~cm}^{-1}\left(189 \mathrm{~cm}^{-1}\right.$ in the $n$ and $i$ phases $)$ is obviously an internal mode, most probably due to a torsional motion. The intermolecular forces perturbing this normal mode appear slightly different in the liquid-crystalline and the crystalline states. On the other hand, the nematic and the isotropic states are characterized more by order or lack of it than by significant changes of intermolecular forces.

Figure 2 displays the integrated intensity of the lattice bands as a function of temperature. Both the $c-n$ and $n-i$ transitions can be determined from this plot. While the former transition indicates a hysteresis effect, the latter does not. As far as it can be determined, the area of the hysteresis loop was not a function of the rate of heating or cooling. In one experiment, after freezing MBBA, it was warmed up to $12.5^{\circ} \mathrm{C}$ and

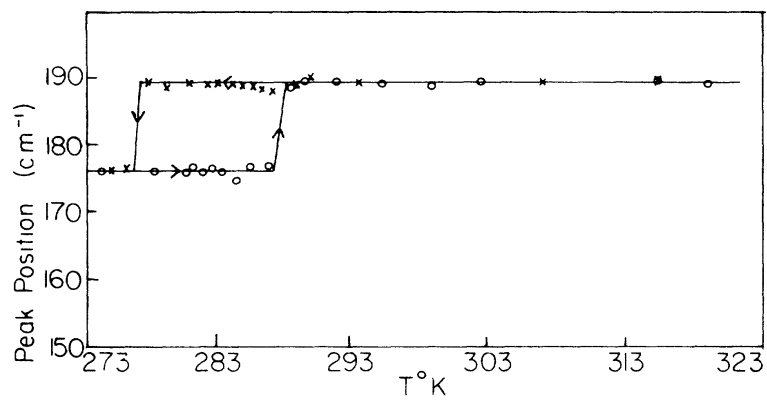

FIG. 3. Peak frequency of the Raman band due to an internal mode versus temperature. Circles represent heating; crosses, cooling.

kept at this temperature for $24 \mathrm{~h}$, and no phase transition to the nematic state was noted. Similarly, after heating the sample to the liquid-crystal state it was cooled to $5.3^{\circ} \mathrm{C}$ and held constant for $24 \mathrm{~h}$. Again the liquid crystal remained in the nematic state. The frequency of the internal mode as a function of temperature is plotted in Fig. 3, which also shows the hysteresis phenomenon for the $c \rightarrow n$ transition. It has not yet been ascertained whether this hysteresis is dependent on the shape and size of the container. Such studies are in progress.

We are grateful to Dr. G. Lengyel and Dr. S. V. Letcher for helpful discussions. Thanks are also due to D. W. Galipeau for technical assistance.

${ }^{1} \mathrm{~J}$. P. Le Pesant and P. Papon, in Proceedings of the Third International Conference on Liquid Crystals, Berlin, September 1970 (to be published).

${ }^{2}$ J. Rault, P. E. Cladis, and J. P. Burger, Phys. Lett. A32, 199 (1970).

${ }^{3} \mathrm{H}$. Kelker and B. Scheurle, Angew. Chem. $\underline{8}, 884$ (1969).

${ }^{4}$ I. Haller and J. D. Litser, Phys. Rev. Lett. 25, 1550 (1970).

${ }^{5}$ T. W. Stinson and J. D. Litser, Phys. Rev. Lett. $\underline{25}$, 503 (1970).

${ }^{6}$ B. J. Bulkin, D. Grunbaum, and A. V. Santoro, J. Chem. Phys. 51, 1602 (1969).

${ }^{7}$ N. M. Amer, Y. R. Shen, and H. Rosen, Phys. Rev. Lett. 24, 718 (1970).

${ }^{8}$ B. J. Bulkin and F. F. Prochaska, J. Chem. Phys. 54,635 (1971).

${ }^{9}$ S. Kusabayaski and M. M. Labes, Mol. Cryst. Liquid Cryst. $\underline{7}, 395$ (1969).

${ }^{10} \mathrm{~S}$. V. Letcher and A. J. Varlow, Phys. Rev. Lett. 26, 172 (1971).

11“"High Purity" MBBA from Vari-Light Corporation, Cincinnati, Ohio, was used in this investigation. 